\title{
Museologia e Comunidades LGBT: mapeamento de ações de superação das fobias à diversidade em museus e iniciativas comunitárias do globo Jean Baptista ${ }^{1}$ Tony Boita ${ }^{2}$
}

Resumo: O presente artigo é etapa do projeto Memória LGBT (lésbicas, gays, bissexuais e pessoas trans), responsável pelo mapeamento e análise das principais ações existentes em museus e iniciativas comunitárias da Europa, Américas, África, Ásia e Oceania. Por meio de visitas técnicas, entrevistas não-diretivas (presenciais ou virtuais), publicações da Revista Memória LGBT, pesquisas bibliográficas e consultas a sites oficiais, o mapeamento se propõe a indicar limites e possibilidades que se apresentam ao campo museológico mediante a inclusão de uma minoria presente em todos os continentes. Esta invisibilidade museal, favorece o esquecimento e consequentemente fortalece as fobias à orientação

\footnotetext{
${ }^{1}$ Jean Baptista: Professor Adjunto do Bacharelado em Museologia da Universidade Federal de Goiás (UFG) e Coordenador de Inclusão e Permanência-Prograd-UFG. Líder do Grupo de Pesquisa Comunidades e Museologia Social (ComusasCNPq/Ibram). jeantb@hotmail.com Lert

${ }^{2}$ Tony Boita: Museólogo e professor substituto do Curso de Museologia da UFG. É graduado pela Universidade Federal de Goiás (2015). tonyboita@hotmail.com $\underline{\text { Lert }}$
} 
sexual e identidade de gênero. Ao analisar as técnicas de preservação, o conteúdo expositivo de cada proposta mapeada, bem como sua ausência em amplos territórios, procura-se indicar estratégias encontradas na construção de uma memória LGBT global. Problematiza-se, com isso, a democratização da memória e conteúdos manifestos em museus, iniciativas comunitárias ou políticas museais interessadas na conquista de direitos civis e na superação de fobias à diversidade sexual/afetiva.

Palavras-chave: LGBT, Diversidade, Museologia Social

Abstract: This study seeks an overall view of the memory of the LGBT community (lesbian, gay, bisexual, transgender) in museums and community initiatives, the project LGBT memory mapping and analyzes the main existing shares in Europe, the Americas, Africa, Asia and Oceania. Through technical visits, interviews, non-directive (attendance or virtual), the magazine LGBT Memory publications, bibliographical researches and queries to official sites, mapping aims to indicate the limits and possibilities that are presented to museological field by including a minority present in every continent but still forgotten. This museological invisibility, favors forgetfulness and consequently strengthens phobias of sexual orientation and gender identity. By analyzing the preservation techniques, the exhibition content of each mapped proposal and its absence in large territories, looking to indicate strategies found in building a global LGBT memory, questioning, therefore, the democratization of memory and manifest content in museums, community initiatives or museological policies interested in winning civil rights and overcoming phobias to sexual / emotional diversity. 
Jean Baptista, Tony Boita

Keywords: LGBT, Diversity, Social Museology

\section{Introdução:}

Tendo ao fundo o mar de Ipanema e Copacabana refletindo o pôr do sol, o terraço do Museu de Favela (MUF), no alto do morro do Pavão, Pavãozinho e Cantagalo (PPG), no Rio de Janeiro, recebe Yonne Karr pela primeira vez. Trata-se de uma trans-mulher negra que hoje dubla sucessos de cantoras negras do pop como Whitney Houston, com quem muito se assemelha graças à impecável caracterização. Ao fim da performance, aplausos de uma plateia que celebra a diversidade. Registra-se, com isso, o encerramento do projeto Memória LGBT no MUF.

Yonne é uma das 20 mil pessoas que moram no PPG. Essa favela, encravada em um maciço rochoso entre as praias mais caras do Brasil, tem entre seus aparelhos culturais o MUF, destacável museu comunitário do Brasil interessado na salvaguarda da memória local (SILVA; PINTO; LOUREIRO, 2012). Faltava, até então, incluir a comunidade LGBT do morro em seu conteúdo, conforme vinha indicando Sidney Tartaruga, diretor cultural da instituição. Com duração de seis meses, o projeto Memória LGBT no MUF realizou um conjunto de exposições comunitárias e publicações na Revista Memória LGBT, resultando em ações que promoveram e salvaguardaram no PPG a memória de pessoas como Yonne Karr. "Após tantos anos de apresentações no país", diz Yonne ao agradecer os aplausos, "tive enfim a alegria de fazer um show em minha própria comunidade". 
Do alto do terraço do MUF em festa, percebe-se que cada segundo na favela é história. Da escravização dos países africanos ao tempo da colônia e império, passando pelas intervenções das potências do norte ao longo do século XX e alcançando o cenário conservador no qual o Brasil atualmente mergulha, ali se encontra parte dos resultados de mais um Estado racista e LGBTfóbico do mundo. Minoria entre a minoria, a comunidade LGBT do morro é composta por pessoas negras, economicamente pobres, teimosas em existir e se reconstruir a cada geração, assegurando sua resistência em laços solidários alimentados por uma "memória subterrânea" (POLLACK, 1989, p. 3-15).

Do litoral do Brasil para o mundo, de fato, as coisas não costumam ser fáceis para os LGBT. Por meio de diversos relatórios, instituições como a Organização das Nações Unidas (ONU, 2016), International lesbian, gay, bisexual, trans and intersex association (ILGA, 2016), Human Rights (HR, 2015), entre outras, indicam que a população LGBT é criminalizada em quase 80 países, alguns com pena capital ou perpétua, além de serem submetidos a práticas diárias de humilhação e perseguição. Foi somente no Icom 2013 em que a comunidade museológica internacional se pronunciou por meio da Resolução $\mathrm{n}^{\circ} 4$, Museos, Inclusión e Integración del enfoque de la igualdad entre sexos - em última instância, o documento convida as instituições museológicas a participar dos esforços de superação da hegemônica "matriz heterossexual" (BUTLER, 2013) que reina nos museus.

Ciente dos fatos, mais do que nunca a comunidade museológica é chamada para se posicionar em relação à 
discriminação de pessoas LGBT. Mas quais seriam as instituições que já possuem este comprometimento? Quais as estratégias que empregam para promover memórias subterrâneas e silenciadas? Que possibilidades se abrem às instituições museológicas quando uma minoria até então negligenciada passa a ter suas memórias promovidas e salvaguardadas? A partir dessas problemáticas, o presente artigo tem por objetivo apresentar instituições museológicas e iniciativas comunitárias mapeadas pelo projeto Memória LGBT nos países do norte, África, América Latina, Ásia e Oceania. Por meio de visitas técnicas, entrevistas não-diretivas (presenciais ou virtuais), pesquisa bibliográfica e em sites oficiais, além de publicações da Revista Memória LGBT, construiu-se um mapeamento das instituições que rompem modelos de opressão e esquecimento, ao mesmo tempo em que se evidencia o absoluto descompromisso das demais instituições de memória para com esta população. Longe de querer ser um mapeamento definitivo, apresentam-se, a seguir, museus e iniciativas comunitárias que se conectam a estas preocupações.

\section{Norte}

No pós II Guerra Mundial, instituições como o Gründerzeit Museum, em Berlim, construído a partir da coleção de objetos quotidianos recolhidos pela transexual alemã Charlotte von Mahlsdorf, tornaram-se ponto de encontro para os LGBT do mundo, ainda que muitas vezes clandestinos (MAHLSDOR, 2004; GRÜNDERZEITMUSEUM, 2016). Contudo, é a partir dos anos 80 que as carnalidades ingressam formalmente nos museus, quando se dá a explosão dos museus de sexualidade ou eróticos. Museu Erótico 
em Amsterdã (1985), Museu Erótico de Barcelona (1997), MoSex em Nova York (2002), entre outros, são alguns exemplos dessa tipologia onde a temática LGBT está inserida em meio às múltiplas sexualidades da humanidade.

Contudo, uma outra tipologia de museus voltada à salvaguarda da memória da luta das comunidades LGBT pelos direitos civis reivindica seu espaço. Neste sentido, avanços significativos foram localizados nos EUA. O Leslie-Lohman Museum of Gay and Lesbian Art, em Nova York, acumula desde 1969 talvez a maior coleção de obras de artistas LGBT do mundo, ampliada, sobretudo, durante a pandemia da SIDA, quando as obras de artistas mortos pela doença desvalorizaram ou até mesmo foram encontradas no lixo (WEIERMAIR, 2008; LESLIE-LOHMAN MUSEUM OF GAY AND LESBIAN ART, 2000). Nascido em 1973 de uma biblioteca particular do reconhecido ativista Mark Silber, o National Museum \& Archives Stonewall, na Flórida, sobreviveu a inúmeras polêmicas sobre seu acervo, entre elas a de ser acusado de conter material pornográfico em 2007, seguindo assentado como uma das instituições mais completas do ramo naquele país (NATIONAL MUSEUM \& ARCHIVES STONEWALL, 2016). Já o Tucson LGBTQ Museum, Arizona, começou a ser gestado em forma de arquivo desde os anos 60, realizando inúmeros projetos voltados à memória da violência contra os LGBT e políticas de prevenção a SIDA nos anos altos da pandemia (TUCSON GAY HISTORICAL SOCIETY, 2016). Desde 2011, no Castro, São Francisco, encontram-se exposições destinadas à história da libertação da comunidade no GLBT History Museum (BAUTISTA, 2014, p. 87; GLBT HISTORY MUSEUM, 2016). Com a missão de dimensionar "uma História que une milhões de pessoas, mas 
Jean Baptista, Tony Boita

raramente é representada nos museus tradicionais", o Museu Nacional LGBT em Whashington, anuncia em 2013 que se tornará uma das maiores referências mundiais sobre o tema. Outras dezenas de iniciativas em museus dos EUA inserem a questão LGBT em suas exposições e eventos, sobretudo durante o governo Obama, não por acaso um dos políticos mais influentes no combate à LGBTfobia tanto nos EUA quanto fora dele (NATIONAL LGBT MUSEUM, 2016). Nos EUA, portanto, o que se vê são movimentos sociais interessados em salvaguardar sua memória e construir arquivos, exposições e conteúdos que sustentem argumentos interessados na conquista de direitos civis. Não raro, estas instituições possuem seu ponto de partida ou marco inicial o Stone Wall, insurreição de 1969 que deu origem à manifestação LGBT mais difundida no mundo, a Gay Pride.

Na Europa, o Schwules Museum, em Berlim, inaugurado em 1985, promove o protagonismo LGBT produzindo exposições sobre artistas e personalidades, bem como sobre marcos da história LGBT, tal qual a perseguição nazista e o descaso global mediante os anos quentes da epidemia de SIDA (STERNEWEILER, 2004). A importância do Schwules no cenário museológico deu novo fôlego para outras vivências no continente. Com certeza são significativas as iniciativas como a do popular Museu de Cera Madame Tussaud de Londres, que em 2006 ganhou uma ala gay, e a do Museu Britânico, que lançou em 2013 uma importante publicação que retrata peças da história LGBT - não levou, ao fim, a realização uma exposição temporária no museu com este mesmo acervo (PARKINSON, 2013). Uma controversa contribuição partiu do Museu de História Natural de Oslo com a exposição "Contra a 
natureza?", onde viam-se "animais homossexuais" (NATURAL HISTORY MUSEUM, UNIVERSITY OF OSLO, 2006). Museus virtuais como The Unstraight Museum, na Suécia, nascido em 2011 a partir da insatisfação de profissionais de museus mediante o silenciamento sobre a questão LGBT, valem-se da interatividade para construir novos acervos (THE UNSTRAIGHT MUSEUM, 2016).

Como se percebe, em solo europeu parece haver imensas dificuldades para se criar ações museológicas que abordem diretamente a memória LGBT. Na Espanha, por exemplo, a Asociación Cultural Visible (ACV), liderada por Pablo Pinedo, propôs a criação de um Museu Nacional de Arte Gay, sem sucesso no que se refere à geração de um espaço físico - criaram, ao fim, uma exposição internacional itinerante (talvez a primeira do mundo) entre 2008 e 2009, o documentário Arte Gay busca Casa e a página virtual Visible Art Gay, onde se apresenta o acervo do museu. Diversas ações de outros movimentos sociais em Espanha tem se valido de exposições que retratam a história e memória LGBT, como realizou em 2007 o Coletivo LGTB de Madrid, por meio da exposição "El camino hacia la igualdad: 30 años de lucha por los derechos LGTB en el Estado Español" (VISIBLE ASSOCIACIÓN CULTURAL, 2016).

Recentemente elevado a um país seguro aos LGBT, Portugal criminaliza a homofobia desde 2007, permite a adoção por casais do mesmo sexo e introduz a identidade de gênero em seu Código do Trabalho, mas não possui nenhuma iniciativa museológica formal interessada na questão LGBT. Sem dúvida, o projeto de maior alcance relacionado à memória provém do grupo Opus Gay, 
liderado pelo militante veterano Antonio Serzedelo, um dos autores do o Manifesto "Liberdade para as Minorias Sexuais", de 1974, marco da luta por direitos civis no país. Intitulado Envelhecer Fora do Armário, o projeto desenvolveu uma exposição de distintos artistas que retratam a terceira idade LGBT, etapa apresentada como um momento de maior fragilidade desta comunidade. Com apoio da Câmara Municipal de Lisboa, a exposição não encontrou abrigo em instituições museológicas, mas, sim, na Biblioteca Arquitecto Cosmelli Sant'Anna, da Freguesia de Santo António, realizadora de distintas ações inclusivas.

Outra importante organização presente em Portugal e que se utiliza da memória da violência em seus discursos e produções é a International lesbian, gay, bisexual, trans and intersex association Portugal. Além da produção de relatórios anuais e ações civis em prol da defesa dos direitos humanos, a entidade internacional assentou-se em terras lusitanas onde criou o Centro LGBT, em Lisboa, importante espaço de convivência, debates, teatro, oficinas e até mesmo um coral. Neste mesmo centro funciona o único projeto formal encontrado em Portugal voltado à salvaguarda da memória LGBT: desde a sua criação, em 1998, o Centro de Documentação Gonçalo Diniz disponibiliza um vasto acervo de livros, revistas, trabalhos de investigação, vídeos, recortes de jornais, entre outros materiais, sobre a temática LGBT (ILGA PORTUGAL, 1998).

\section{África}

A situação da população LGBT da África tem sido denunciada por organismos internacionais e frágeis movimentos 
locais como o pior continente do mundo para esta população. 0 relatório "Fear for Life: Violence against Gay Men and Men Perceived as Gay in Senegal,", da Human Rights Wach, de 2010, por exemplo, denunciou as sucessivas práticas senegalesas de assassinato, tortura, criminalização no sistema judiciário e maustratos (HUMAN RIGHTS WACH, 2010). Lideranças africanas, por sua vez, costumam proferir falas públicas onde afirmam que os direitos humanos pregado pelo Ocidente não pertence às culturas locais, devendo, portanto, ser ignorado em suas políticas.

Nos Países Africanos de Língua Oficial Portuguesa (PALOP) não há pena de morte oficial, mas não raro há penalizações. Em Angola, por exemplo, a legislação não atualizada segue ignorando a população LGBT, havendo brechas para que membros da comunidade possam ser penalizados por ato ilegal, o que resultaria, como defende a ILGA, o envio de pessoas para trabalhos forçados o governo nega. Contudo, ativistas do país seguem denunciando práticas recorrentes de desrespeito à diversidade, tal qual o faz José Patrocínio, coordenador da Omunga, uma das principais organizações de defesa dos direitos humanos do país. Na mesma situação encontram-se a Guiné-Bissau e Moçambique. Neste cenário, o presente mapeamento localizou apenas dois países africanos que demonstram alguma possibilidade de avanços em relação à memória da comunidade LGBT: África do Sul e Cabo Verde.

Primeiro país a incluir homossexuais em sua constituição, posteriormente autorizando o casamento entre pessoas do mesmo sexo e criando leis anti-homofobia, a África do Sul se tornou, 
segundo a agência da ONU para refugiados (AGÊNCIA DA ONU PARA REFUGIADOS, 2015), o destino mais procurado pelos chamados "asilados sexuais" do continente. A exposição temporária de 2016, Journeys of Faith, que retrata a luta do movimento LGBT no país, ganhou espaço no Museu do Apartheid, em Joanesburgo. A exposição referia-se a MaThoko, mulher heterossexual dona de uma taverna na cidade de KwaThema que abrigou jovens LGBT vítimas de perseguição familiar, policial ou em situação de vulnerabilidade durante os anos altos da política discriminatória. A notícia se espalhou e sua caixa de correio passou a receber centenas de cartas de LGBT relatando as violências a que estavam submetidos. A partir deste mote, a exposição busca cartas que circulavam entre o movimento LGBT de então, identificando a intersecção entre racismo e homofobia, abordagem rara em nos demais museus investigados pelo presente mapeamento.

Em Cabo Verde, por outro lado, nenhuma instituição museológica envolveu-se com a questão até o momento, mas um jovem movimento social LGBT local passou a reivindicar a memória em suas ações. A primeira parada LGBT em 2012 no arquipélago foi uma anomalia na trajetória dos países africanos, sediada no Mindelo e organizada pela Associação Gay Cabo-Verdiana. A edição posterior da parada, em 2013, foi contemplada por uma significativa exposição intitulada Musas: retrato da comunidade gay de São Vicente, de autoria da fotógrafa alemã-caboverdiana Julliette Brinkmann (ASSOCIAÇÃO GAY CABOVERDIANA, 2013). Há décadas residindo em São Vicente, Brinkmann retratou o cotidiano, a performance, o processo de montagem, sonhos e desafios desta comunidade. Marco das estratégias expositivas do continente 
africano, as Musas caboverdianas, com seus olhares sofridos e marginais, parecem alertar à museologia que o silêncio dos museus africanos tem sido voraz colaborador do cenário de extermínio reinante naquele continente.

\section{América Latina}

Na América Latina, território de atrozes denúncias contra a comunidade LGBT pautadas em argumentos legais e religiosos, os museus seguem comprometidos com o silêncio. Embora a Argentina, Chile e Uruguai apresentem propostas gay friendly com singelas intervenções, somente no Peru e no Brasil foram localizadas instituições museológicas ou iniciativas comunitárias onde a questão LGBT é abordada com compromissos relacionados à democratização da memória e conquista de direitos civis desta população.

Em 2003, o Museu Travesti no Peru nasce como a primeira prática museal onde o recorte trans é privilegiado, sendo até hoje referência única sobre o tema. Giuseppe Campuzano, morto em 2013, idealizador e diretor da instituição, possuía em seu próprio corpo os pilares do acervo e na história do Peru os fundamentos da vertente trans dos museus. "O Museu Travesti do Peru nasce da necessidade de uma história própria", disse Giuseppe, "ensaiando uma arqueologia das maquiagens e uma filosofia dos corpos para propor uma elaboração de metáforas mais produtivas que qualquer catalogação excludente". Na vanguarda do debate, Campuzano se travestiu em Virgem Maria, deusas incaicas, virgens destinadas a sacrifícios ritualístico de antigos povos indígenas. Na metáfora, denuncia o racismo e a transfobia católica, estatal, peruana, latino- 
Jean Baptista, Tony Boita

americana, o não-lugar de cada um de nós LGBT de todo mundo. Embora a transfobia tenha determinado a exclusão do pensamento trans da produção museológica, Campuzano demonstrou que a capacidade de transicionar está no corpo da museologia. De fato, nos museus transicionamos patrimônio, reencontramos suas identidades em espaços contemporâneos e travestimos os objetos com novos sentidos. O Museu, é de fato, um espaço travesti (REVISTA MEMÓRIA LGBT, 2014; BAPTISTA; BOITA, 2014; MUSEO TRAVESTI DEL PERÚ, 2008).

Quanto ao Brasil, "um cenário favorável à diversidade museal" (CHAGAS, 2013) tem apresentado importantes avanços para a memória dos povos indígenas, negros, quilombolas e outras minorias, mas enfrenta oposições severas quando o assunto é a comunidade LGBT. O país já contava com o Museu da Sexualidade, em Salvador, desde 1989, organizado pelo antropólogo e historiador Luiz Mott, fundador do Grupo Gay da Bahia (GGB) - de caráter universal, o museu enfrentou sérias dificuldades e encontra-se fechado há alguns anos, deixando uma contribuição inquestionável à museologia brasileira, tradicionalmente pudica e assexuada. As dificuldades se intensificam quando o debate museológico passa a se associar ao patrimonial. Bom exemplo disso é o esforço em manter o Baile das Chiquitas, festa profana de travestis lotada em uma das maiores comemorações cristãs do país, o Círio de Nazaré, em Belém do Pará - ainda que o inventário que patrimonializou o festejo em 2004 as tenha incluído (IPHAN, 2006) e o Museu do Círio também, muito em virtude do empenho do movimento social local, até hoje forças políticas conservadoras 
empenham-se em banir da cidade o que é o primeiro patrimônio LGBT reconhecido pelo Brasil (LUIZ, 2015).

Foi preciso aguardar até o V Fórum Nacional de Museus, realizado em Petrópolis, em 2012, para que uma importante mobilização por parte de profissionais de museus ocorresse: paralelamente ao evento, integrantes de universidades, Pontos de Memória ou de museus convencionais reuniram-se para debater a ausência LGBT nas políticas nacionais de memória e em museus. O grupo reunido articulou-se para criar a Rede LGBT de Memória e Museologia Social do Brasil, agremiação que passou a ser uma central crítica de ações e análises sobre a matriz heterossexual da museologia brasileira.

É, portanto, a partir de 2012, que surge no Brasil um conjunto de repercussões criativas que pressionam a inserção da temática LGBT nos museus brasileiros. Um importante momento desta movimentação foi a Semana do Babado, no Museu das Bandeiras (Muban- Ibram), na Cidade de Goiás. Integrante de um amplo projeto afirmativo liderado pela então diretora do Muban, a museóloga Girlene Chagas Bulhões, contando com integrantes da Rede LGBT em Memória e Museologia Social do Brasil e tendo os autores deste artigo como parte da equipe de organização, montou-se a primeira exposição temporária em museus mantidos com fundos federais que contemplasse a história e a memória LGBT do país. Ao longo da semana de debates, realizaram-se rodas de conversas, performances de dragqueens, filmes e uma imensa bandeira LGBT foi erguida na fachada do prédio. Entre os visitantes, a positiva sensação de se ver representado em um importante 
espaço de memória. Uma vez que o museu, originalmente destinado à manutenção da identidade dos bandeirantes, conhecidos facínoras da história nacional, já havia recentemente realizado atividades voltadas a outras minorias, o Museu das Bandeiras passara a ser o Museu de Todas as Bandeiras. Mais uma vez setores conservadores e religiosos manifestaram-se com ferocidade e, infelizmente, poucos meses depois, a diretora do museu foi exonerada de sua função.

Ainda em 2012, na cidade com as maiores taxas de homicídios contra a população LGBT do país, integrantes do movimento local, entre eles Dino Alves, montaram uma exposição onde personalidades da comunidade foram lembradas e homenageadas por meio de fotografias oriundas do cenário noturno da cidade. A exposição rendeu ao grupo o título de Ponto de Memória, tornando-se a primeira iniciativa comunitária LGBT reconhecida pelo Ibram. Também data de 2012 a abertura do Museu da Diversidade Sexual, em São Paulo, um museu sub-way na estação do metrô na Praça da República. Sua primeira exposição, O T da Questão, dedicada às travestis e transexuais paulistas, já indicava o foco que a instituição seguiria para as próximas atividades: as performances culturais de personalidades e grupos artísticos que marcaram a cena paulistana (MUSEU DA DIVERSIDADE SEXUAL, 2012).

No ano seguinte, em 2013, é lançada a Revista Memória LGBT, integrante do projeto Memória LGBT. Em variadas edições, a Revista passou a publicar matérias sobre a memória, patrimônio e história LGBT no Brasil, além de promover exposições virtuais sobre 
variados temas interseccionados com classe e raça. Também passou a realizar projetos em comunidades, tal qual o projeto Memória LGBT no Museu de Favela, que revelou memórias subterrâneas da favela Pavão, Pavãozinho e Cantagalo, contando com três edições especiais (e três exposições em revista), intituladas "Ser Lésbica na Favela", "Ser Gay na Favela" e "Ser Trans na Favela". Além disso, o projeto promoveu o I Seminário Brasileiro de Memória, Museologia e Comunidade LGBT do Brasil, encontro que reuniu distintos profissionais de museus e de memória, bem como integrantes de movimentos sociais. Em conjunto, os resultados revelaram a imensa distância entre a realidade de pessoas LGBT que pertencem à classe média brasileira quando comparadas com as populações de baixa renda, indicando que a museologia e memória LGBT produzida no Brasil tem suas particularidades e necessita estar associada ao critério de classe e raça para estar melhor conectada com a realidade nacional (REVISTA MEMÓRIA LGBT, 2013).

Outros museus no Brasil estão gradualmente interessandose pelo tema. O Museu da Pessoa incluiu relatos as pessoas trans no acervo TransHistórias, que, segundo a instituição, "objetiva resgatar a memória e a dignidade de indivíduos vítimas de tráfico humano, exploração, violência, DST/HIV/AIDS e discriminação, que têm seus direitos humanos, civis e políticos fundamentais expropriado" (MUSEU DA PESSOA, 2014). O apoio prestado pelo Museu da República, no Rio de Janeiro, ao tema LGBT passou a ser inestimável para as movimentações do Brasil. Promovendo debates, seminários e instigando estudos, a instituição passou a ser um importante aliado na superação das fobias à diversidade no 
país. Com curadoria de Mário Chagas, a exposição temporária em homenagem aos 100 anos de Clóvis Bornay apresentou aspectos profissionais e pessoais da vida do importante carnavalesco, ocupando o prédio central do Museu da República, produzindo uma sinalização simbólica positiva sobre o lugar dos LGBT no Brasil (MUSEU DA REPÚBLICA, 2016).

\section{Ásia e Oceania}

Sem dúvida, o terreno de maior dificuldade para a presente pesquisa está sendo o continente asiático. Seja pela barreira linguística, seja pelas distâncias culturais, as informações aqui fornecidas são preliminares e carecem de intercâmbio com os profissionais daqueles países para sua melhor compreensão. Vale alertar que a existência de museus de sexualidade não são uma novidade no continente, mas até o momento não se encontrou museus dedicados à conquista de direitos civis naquele território.

De todo modo, a internet tem colaborado para a reunião de informações, tal qual a organização Utopia o faz. Em sua página, encontra-se uma galeria destinada "a exposições de arte sobre o corpo masculino" produzida por artistas asiáticos e internacionais - a página possibilita uma compreensão ampla do desenvolvimento da arte homoerótica nos países asiáticos (UTOPIA ASIAN GAY \& LESBIAN RESOURCES, 2004). Em Taiwan, em 2003 e 2004, o diálogo entre Taiwan Tongzhi Hotline Association e a Galería Gingins en Taipei realizaram a exposição La mirada sobre los otros - un rompecabezas artístico sobre la historia de lesbianas y gays (CHENG, 2011; BOITA, 2014). Já em Phnom Penh, Camboja, em parceria com movimentos sociais locais e o The Unstraight 
Museum, verificou-se a realização da exposição Rainbow Life, ainda em 2015, que contou com um conjunto de relatos de LGBT do país em um esforço para visibilizar a população (RAINBOW LIFE, 2015).

Na Oceania, Austrália e Nova Zelândia possuem ações diferenciadas. Na Austrália existe a Political, social and cultural differences between gay man and lesbians para os museus nacionais australianos (MUSEUMS AUSTRALIA, 1999, p.7). Como resultado de uma política de âmbito nacional, percebe-se a presença "individual and collective responses from gay and lesbian communities can produce art and artefacts which are relevant to museum collections and programs and must be represented if a balanced view of society and culture is to be achieved". Nesta abordagem, os museus devem elaborar programas e políticas que dialoguem, promovam e preservem as memórias não normativas. Nas páginas oficiais do National Museum Austrália, em Camberra, e do Western Australian Museum, por exemplo, percebem-se interfaces com a história do movimento social e suas trajetórias australianas, em uma incorporação transversal bastante interessante para museus que não possuem em sua missão a questão LGBT como tema central (WESTERN AUSTRALIAN MUSEUM, 2015; NATIONAL MUSEUM AUSTRALIA, 2016; BOITA, 2014).

Já na Nova Zelândia, destaca-se o Charlotte Museum Trust, situado na cidade de Auckland. Trata-se de um museu exclusivamente lésbico que se apresenta da seguinte forma: "The Charlotte Museum Trust is part of a network of archives preserving lesbian culture for the benefit and understanding of future generations" 
Jean Baptista, Tony Boita

(CHARLOTTE MUSEUM TRUST, 2016). Ao que tudo indica, o Charlotte Museum Trust possui exposições de longa e curta duração, além de eventos, seminários e ações educativas culturais voltados exclusivamente à temática lésbica, formato raro no globo.

\section{Considerações finais}

O surgimento de museus, exposições e ações diretas interessadas na memória das comunidades LGBT em nível global atestam que a temática está, gradualmente, assentando-se como tema no campo museológico. Contudo, ainda há muito o que se avançar em um planeta onde a maioria dos países não possuem qualquer ação voltada à memória desta população.

As iniciativas mapeadas revelam um amplo campo a ser explorado, onde uma minoria presente em todos os continentes encontra nos museus a possibilidade de alertar sobre um longo processo discriminatório que atravessa a história da humanidade, chegando aos dias de hoje como uma das maiores vergonhas que as sociedades tem a enfrentar.

Ao comprometer a museologia com a superação da fobia aos LGBT, distintas estratégias já são apontadas pelas ações aqui identificadas. A positivação de personalidades históricas tem sido uma das mais recorrentes, fundamentando-se no impacto sóciopedagógico que poderia representar ter algum cientista, artista ou político já reconhecidos pela memória nacional dos países. Há, também, o que muito nos interessa, uma museologia que pensa na pessoa anônima e suas comunidades - as ações realizadas no MUF demonstram que há radicais diferenças de pautas e vivências 
quando investigamos a memória LGBT a partir de recortes de classe e raça, sobretudo no Brasil, o que aponta para a necessidade de um evolvimento mais amplo por parte da Museologia Social. Eventos históricos de destaque universal também não escapam: a perseguição aos homossexuais ao tempo do nazismo, a intersecção entre negritude e homossexualidade nas ditaduras africanas e latino-americanas, por exemplo, possuem um potencial educativo infindável. O esforço em reunir artefatos, reportagens e outros documentos, bem como a produção de pesquisas, é marca indelével de boa parte das ações identificadas. Majoritariamente, ou sempre que possível, as ações não se negam a falar da resistência LGBT, das trajetórias dos movimentos sociais, da perseguição política e teocrática e das dificuldades de acesso aos direitos civis, tal qual acesso à educação e saúde (sobretudo quando o tema é a pandemia de SIDA) - a memória da violência, é, de fato, o principal mote das estratégias identificadas. Em conjunto, pode-se falar que boa parte destes espaços nascem de organizações ativistas e que já existe um farto material relacionado à memória da população LGBT mas que, de fato, ainda não foi incorporado aos mais variados museus do mundo.

Ao fim, o que se apreende até o momento por meio deste mapeamento é que as comunidades LGBT globais estão empenhadas em construir um conjunto de saberes e práticas, onde a museologia e a memória tornam-se instrumentos estratégicos de manifestação e resistência, interessadas em contribuir para uma sociedade mais justa e igualitária, ainda que vivendo em contextos extremos e violentos. 
Jean Baptista, Tony Boita

\section{Referências Bibliográficas}

AGÊNCIA DA ONU PARA REFUGIADOS. Perseguidos por sua orientação sexual, refugiados LGBTI conseguem proteção no Brasil. 2015. Disponível em: <http://www.acnur.org/t3/portugues/noticias /noticia/perseguidos-por-sua-orientacao-sexual-refugiados-Igbticonseguem-protecao-no-brasil/> Acessado em: 20 abr. 2016. APARTHEID MUSEUM. Journeys of Faith. 2016. Disponível em: <http://www.apartheidmuseum.org/>. Acesso em: 20 maio 2016. ASSOCIAÇÃO GAY CABOVERDIANA. Home. 2013. Disponível em: <http://associacaogaycaboverdiana.blogspot.com.br/>. Acesso em: 20 abr. 2016.

BAPTISTA, Jean; BOITA, Tony. Protagonismo LGBT e museologia social: uma abordagem afirmativa aplicada à identidade de gênero. Cadernos do Ceom. Chapecó, v. 27, n. 41, p.175-192, dez. 2014. Disponível em: $<$ http://bell.unochapeco.edu.br/revistas/index.php/rcc/article/view /2602>. Acesso em: 12 abr. 2016.

BAUTISTA, Susana. Museums in the Digital Age: Changing Meanings of Place, Community, and Culture. Maryland, Altamira Press, 2014. BOITA, Tony. Memória LGBT: Mapeamento e Musealização em Revista. 2014. 62 f. TCC (Graduação) - Curso de Museologia, Ufg, Goiânia, 2014. Disponível em: <https://www.cienciassociais.ufg.br /up /106/ o/TCC_Tony_Museologia_UFG_2014.pdf>. Acesso em: 01 maio 2016. 
Museologia e Comunidades LGBT

CANADIAN MUSEUM OF HISTORY. Canadian Museum Of History Signs Collaboration Agreement With Canadian Lesbian And Gay Archives. 2014.

Disponível em: <http://www.historymuseum.ca/media/canadianmuseum-of-history-signs-collaboration-agreement-with-canadianlesbian-and-gay-archives/>. Acesso em: 15 maio 2014.

CANADIAN LESBIAN AND GAY ARCHIVES. Home. 2015. Disponível em: <http://www.clga.ca/>. Acesso em: 21 fev. 2016.

CHAGAS, Mário. Museu, Memórias e Movimentos Sociais. Revista Museu. 2013.

CHARLOTTE MUSEUM TRUST. Home. 2015. Disponível em: $<$ http://charlottemuseum.lesbian.net.nz/>. Acesso em: 2 mai. 2016. CHENG, Pang-yen. Del diálogo a la comprensión: un caso de estudio sobre la curaduría de una exposición sobre gays y lesbianas taiwaneses.. El Museo Dialógico y La Expeirencia del Visitante, 2011, v. 01, n. 40, p.26-35.

GLBT HISTORY MUSEUM. Museum. Disponível em: <http://www.glbthistory.org/museum/>. Acesso em: 20 abr. 2016. GRÜNDERZEITMUSEUM. Charlotte. Disponível em: $<$ http://www.gruenderzeitmuseum.de/charlotte.html>. Acesso em: 20 mar. 2016.

HUMAN RIGHTS WACH. Fear for Life: Violence against Gay Men and Men Perceived. 2010. Disponível em: $<$ https://www.hrw.org/sites/default/files/reports/senegal1110web wcover.pdf>. Acesso em: 21 nov. 2015.

HUMAN RIGHTS WATCH. Relatório Mundial 2015: África do Sul. 2015. Disponível em: <https://www.hrw.org/pt/worldreport/2015/country-chapters/268110>. Acesso em: 26 fev. 2016. 
Jean Baptista, Tony Boita

ILGA Portugal. Actividades. 1998. Disponível em: <http://ilgaportugal.pt/actividades/centro-documentacao.php> Acesso em: 1 mai. 2016.

ILGA. Relatório. 2016. Disponível em: <http://ilga.org/>. Acesso em: 1 maio 2016.

IPHAN. Círio de Nazaré. Rio de Janeiro: Iphan, 2006. (Dossiê Iphan; 1).

Disponível

em:

$<$ http://portal.iphan.gov.br/uploads/publicacao/PatImDos_Cirio_m. pdf>. Acesso em: 21 abr. 2016.

LESLIE-LOHMAN MUSEUM OF GAY AND LESBIAN ART. Apresentação. 2000.

Disponível em: <https://www.leslielohman.org/>. Acesso em: 21 fev. 2016.

LUIZ, Jaddson. O Baile das Chiquitas: Conflitos e Negociações de um Patrimônio LGBT. Revista Memória Lgbt: Patrimônio Cultural LGBT, Goiânia, p.33-36, abr. 2014. Bimestral. Disponível em: <www.memorialgbt.com>. Acesso em: 05 jun. 2015.

MAHLSDORF, Charlotte Von. I am my own wife: the true story of Charlotte Von Mahlsdorf. São Francisco, Cleis Press, 2004.

MUSEUMS AUSTRALIA. GAY \& LESBIAN POLICY GUIDELINES: FOR MUSEUM PROGRAMS AND PRACTICE. 1999. Disponível em: $<$ http://www.museumsaustralia.org.au/userfiles/file/Policies/glama .pdf>. Acesso em: 20 mar. 2015.

MUSEU DA DIVERSIDADE SEXUAL. Home. 2012. Disponível em: <http://www.mds.org.br/> Acesso em: 20 abr. 2016.

MUSEU DA PESSOA. Coleção TransHistórias. 2014. Disponível em: $<$ http://www.museudapessoa.net/pt/conteudo/colecao/transhistorias-97477>. Acesso em: 20 abr. 2016. 
MUSEU DA REPÚBLICA. XXX Jornada Republicana. 2016.

Disponível em: <http://museudarepublica.museus.gov.br/xxxjornada-republicana/>Acessado em: 20 abr. 2016.

MUSEU DA SEXUALIDADE. Museu. 2003. Disponível em: <http://www.ggb.org.br/museu.html> Acesso em: 20 abr. 2016. MUSEU DE CERA MADAME TUSSAUD. Home. 2015. Disponível em: <https://www.madametussauds.co.uk/london/en/>. Acesso em: 22 abr. 2016.

MUSEUM OF SEX. Collection. 2015. Disponível em: <http://www.museumofsex.com/museum/about/collection/>. Acesso em: 20 abr. 2016.

MUSEO TRAVESTI DEL PERÚ. Apresentação. 1998. Disponível em: $<$ http://hemi.nyu.edu/hemi/en/campuzano-presentation>. Acesso em: 20 abr. 2016.

NATIONAL LGBT MUSEUM. Home. 2016. Disponível em: <http://www.nationalmuseum.nyc> . Acessado em: 20 mai. 2016. NATIONAL MUSEUM AUSTRALIA. About. Disponível em:. <http://www.nma.gov.au/> Acesso em: 2 mai. 2016.

NATIONAL MUSEUM \& ARCHIVES STONEWALL. Home. 2013. Disponível em: <http://www.stonewall-museum.org/>. Acesso em: 20 maio 2016<.

NATURAL HISTORY MUSEUM, UNIVERSITY OF OSLO. AGAINST NATURE?. 2006. Disponível em:<http://www.nhm.uio.no/besokoss/utstillinger/skiftende/againstnature/index-eng.html>Acesso em: 22 abr. 2016.

ORGANIZAÇÃO DAS NAÇÕES UNIDAS. LGBT. Disponível em: <https://nacoesunidas.org/tema/lgbt/>. Acesso em: 13 abr. 2016. PARKINSON, R.B. A Little Gay History. New York, Columbia University Press, 2013 
Jean Baptista, Tony Boita

POLLACK, Michael. Memória, esquecimento e silêncio. In: Estudos Históricos, Rio de Janeiro, v. 2, n. 3, p.3-15, jun. 1989. Tradução de Dora Rocha Flaksman.

RAINBOW LIFE. About. 2015.Disponível em:< http://10december.org/>. Acessado em: 30 nov. 2014.

REVISTA MEMÓRIA LGBT. Apresentação. 2013. Disponível em: <www.memorialgbt.com> . Acesso em: 20 abr. 2016.

. Ser Gay na Favela. Rio de Janeiro, Editora Nós, mai. 2015. Disponível em: <www.memorialgbt.com>. Acesso em: 20 dez. 2015. . Ser Lésbica na Favela. Rio de Janeiro, Editora Nós, mar. 2015. Disponível em: <www.memorialgbt.com>. Acesso em: 20 dez. 2015. . Ode a Campuzano. Rio de Janeiro, Editora Nós, 2014. Disponível em: <www.memorialgbt.com>. Acesso em: 20 nov. 2015.

. Ser Trans na Favela. Rio de Janeiro, Editora Nós, jun. 2015. Disponível em: <www.memorialgbt.com>. Acesso em: 20 dez. 2015. SCHWULES MUSEUM. Home. Disponível em: <http://www.schwulesmuseum.de/>. Acesso em: 26 mar. 2016. SILVA, Carlos Esquiavel Gomes da; PINTO, Rita de Cássia Santos; LOUREIRO, Kátia Afonso Silva. Circuito das Casas-Tela: Caminhos de Vida no Museu de Favela. Rio de Janeiro: Museu de Favela, 2012. STERNEWEILER, Andreas. Self-Awareness and Persistence. Two Hundred Years of History. Schwules Museum, 2004.

THE EROTIC MUSEUM. Apresentação. 2007. Disponível em: <http://www.erotisch-museum.nl/>. Acesso em: 26 mar. 2016. THE UNSTRAIGHT MUSEUM. Home. 2015. Disponível em: <http://www.unstraight.org/>. Acesso em: 20 maio 2016. 
TUCSON GAY HISTORICAL SOCIETY. Home. Disponível em: <http://www.tucsongayhistoricalsociety.org/>. Acesso em: 12 maio 2016.

ULLMANN, Reinholdo Aloysio. Amor e sexo na Grécia Antiga. Porto Alegre, Edipucrs, 2007.

UTOPIA ASIAN GAY \& LESBIAN RESOURCES. Home. 2004. Disponível em: <http://www.utopia-asia.com/>Acesso em: 20 abr. 2016.

VISIBLE ASSOCIACIÓN CULTURAL. Quienes Somos. Disponível em: <http://www.festivalgayvisible.com/index2.html>. Acesso em: 20 maio 2016.

WEIERMAIR, Peter. Treasures of Gay Art from theLeslie/ Lohman Gay Art Foundation's Permanent Collection. All Saints Press, 2008. WESTERN AUSTRALIA MUSEUM. The Gay Museum. Disponível em: <http://www.jodarbyshire.com/uploads/text-files/gay_museum_ catalogue.pdf> . Acesso em: 20 jun. 2015.

Jean Baptista: Professor Adjunto do Bacharelado em Museologia da Universidade Federal de Goiás (UFG) e Coordenador de Inclusão e Permanência-Prograd-UFG. Líder do Grupo de Pesquisa Comunidades e Museologia Social (Comusas-CNPq//bram).Participa desde 2006 de projetos sobre a questão indígena no Museu das Missões. Integra a Rede LGBT de Memória e Museologia Social do Brasil e a Rede de Pontos de Memória e Iniciativas Comunitárias em Museologia Social do RS (RepimRS). É parecerista dos Anais do Museu Histórico Nacional e integrante do Conselho Editorial da Revista Memória LGBT. De 2010 a 2013, foi Professor Adjunto na Universidade Federal do Rio Grande (FURG), onde compôs a Comissão de Ações Afirmativas da FURG e o Núcleo de Estudos 
Afro-Brasileiro e Indígena da FURG (Neabi), além de ter coordenado o Programa de Extensão Comunidades FURG (Comuf) com financiamento do edital Proext 2012 e 2013. Possui graduação em História (Licenciatura e Bacharelado) pela Pontifícia Universidade Católica do Rio Grande do Sul (2001), mestrado (2004) e doutorado (2007) pelo PPGH da Pontifícia Universidade Católica do Rio Grande do Sul. Possui experiência na área de História e Museologia Social, atuando a partir de temas como Ações Afirmativas, Patrimônio e Extensão Universitária, com ênfase em cultura e desenvolvimento local de grupos vulneráveis brasileiros. jeantb@hotmail.com

Tony Boita: Museólogo e professor substituto do Curso de Museologia da UFG. É graduado pela Universidade Federal de Goiás (2015). Em 2012, atuou no programa de formação de guias turísticos e professores da rede de ensino promovido pelo Museu das Missões (Ibram) em parceria com a prefeitura de São Miguel das Missões. Entre 2010-2013, foi coordenador de Museologia Social do Programa de Extensão Comunidades FURG (Proext-Mec), atuando entre comunidades indígenas e quilombolas do extremo sul do Rio Grande do Sul em vista de seu reconhecimento patrimonial e territorial. Em 2013, foi contemplado em primeiro lugar com o prêmio agente jovem de cultura ( SCDC/MinC) pelo projeto Mulheres do Vale Araguaia. Em 2014, foi consultor do Ponto de Cultura Fica aí Dizendo, clube social negro de Pelotas. Neste mesmo ano, foi consultor do projeto premiado Mestre de Cultura Popular, concedido a Mestre de Cultua Dona Sinhá. Atualmente, é editor da Revista Memória LGBT, membro do Conselho de Gestão Participativa e Compartilhada do Instituto Brasileiro de Museus (Ibram) e articulador da Rede LGBT de Memória e Museologia Social. Coordena o projeto Memória LGBT no Museu de Favela, Pavão, Pavãozinho e Cantagalo, financiado pela Secretaria Municipal de Cultura do Rio de Janeiro em comemoração aos 450 anos da cidade. Coordena, também, o projeto Patrimônio Cultural LGBT e Museus: mapeamento, limites e possibilidades de memórias negligenciadas no Grupo de Pesquisa 


\section{Museologia e Comunidades LGBT}

Comunidades e Museologia Social COMUSAS (Ibram/CNPq): extensão universitária e ações afirmativas entre comunidades negras, indígenas, quilombolas, periféricas e LGBT. Atua principalmente com os seguintes temas: Museologia Comunitária, Museologia Afirmativa, Museologia Social, Memória e Patrimônio Cultural de grupos vulneráveis, Cultura Popular e Interdisciplinaridade tonyboita@hotmail.com 